\title{
PESTICIDAS: MECANISMO DE AÇÃO, DEGRADAÇÃO E TOXIDEZ
}

\author{
CLÁUDIA F. B. COUTINHO* \\ SONIA T. TANIMOTO* \\ ANDRESSA GALLI* \\ GUSTAVO S. GARBELLINI* \\ MARISA TAKAYAMA** \\ RAQUEL B. DO AMARAL ** \\ LUIZ H. MAZO*** \\ LUIS A. AVACA ${ }^{* * *}$ \\ SERGIO A. S. MACHADO***
}

\begin{abstract}
Este artigo apresenta breve revisão sobre pesticidas muito utilizados no Brasil em culturas de soja, milho e cana-de-açúcar. Foram abordados o mecanismo de ação, a degradação e a toxidez dos herbicidas glifosato, pendimetalina e atrazina e dos inseticidas fenitrotion e fipronil. Verificou-se que o modo de ação desses pesticidas ocorre por meio da inibição de enzimas específicas como a enolpiruvil shikimato3-fosfato sintase (glifosato) e a colinesterase (fenitrotion), de proteínas como as tubulinas (pendimetalina), de receptores do sistema nervoso como o ácido gama aminibutírico (fipronil) e da inibição da fotossíntese (atrazina). Em relação à degradação, a rota mais importante para o desaparecimento dos herbicidas glifosato e atrazina e do inseticida fenitrotion é a biodegradação. Fipronil, moderadamente persistente no ambiente, é degradado pela luz (fotodegradação). Para a pendimetalina, tanto os microrganismos quanto a luz são responsáveis pelo desaparecimento desse composto. A toxidez dos pesticidas varia de acordo com o grupo químico em que se enquadram, sendo o efeito tóxico mais agudo para os seres humanos e outros mamíferos apresentado pelo fenitrotion (organofosforado).
\end{abstract}

PALAVRAS-CHAVE: AGROTÓXICOS - MECANISMO DE AÇÃO; DEGRADAÇÃO; AGROTÓXICOS -TOXIDEZ.

* Doutorandos em Química Analítica, Instituto de Química de São Carlos (IQSC), São Carlos-SP (email: claudiabreda@iqsc.usp.br).

** Mestrandos em Química Analítica, IQSC, São Carlos-SP.

*** Pesquisadores, IQSC, São Carlos-SP (e-mail: Ihmazo@iqsc.usp.br; avaca@iqsc.usp.br; sasmach@iqsc.usp.br). 


\section{INTRODUÇÃO}

A qualidade da produção agrícola sempre foi intensamente afetada pelo aparecimento de formas de vida indesejáveis, tais como insetos e ervas daninhas. Desta forma, tornou-se necessária a utilização de agrotóxicos ou pesticidas de diversas classes químicas. Os primeiros grupos químicos utilizados como pesticidas foram substâncias tóxicas de origem natural, tais como o piretro e a nicotina, além de elementos inorgânicos como o mercúrio e o enxofre (JONATAN, 1989).

Os agrotóxicos são divididos em diferentes classes, dentre as quais pode-se citar herbicidas, fungicidas, acaricidas, algicidas, larvicidas e inseticidas. Suas funções básicas na agricultura incluem a elevação da produção com aumento da produtividade, a melhoria da qualidade dos produtos e a redução do trabalho e dos gastos com energia. Sem dúvida esses objetivos foram alcançados nas últimas décadas. No entanto, o uso indiscriminado e pouco criterioso de agrotóxicos trouxe e continua trazendo problemas muitos sérios para o ambiente e para a saúde humana. Dados estatísticos da Associação Nacional de Defensivos Agrícolas (ANDEF) mostram que o uso de pesticidas dobrou de volume na década de 90 , sendo que os herbicidas representam cerca de $85 \%$ desse aumento (SILVA, 1999).

A venda total de agrotóxicos, em 2004, atingiu US $\$ 4,495$ bilhões, $43,3 \%$ a mais em faturamento do que em 2003 de acordo com o Sindicato Nacional da Indústria de Produtos para Defesa Agrícola (Sindag). O consumo desses produtos difere nas várias regiões brasileiras, nas quais se misturam atividades agrícolas intensivas e tradicionais. Pela elevada quantidade total de herbicidas usados, as culturas da soja, milho e cana-de-açúcar merecem atenção por ocuparem extensas áreas no Brasil (RONAN, 2004).

Este artigo apresenta breve revisão sobre pesticidas muito utilizados no Brasil em culturas de soja, milho e cana-de-açúcar. Foram abordados o mecanismo de ação, a degradação e a toxidez dos herbicidas glifosato, pendimetalina e atrazina e dos inseticidas fenitrotion e fipronil.

\section{AMINOÁCIDOS FOSFONADOS}

Único representante do grupo dos aminoácidos fosforados com real importância, o glifosato foi sintetizado a partir da substituição de um hidrogênio amínico do aminoácido glicina pelo radical metilfosfônico.

Glifosato [N-(fosfonometil)glicina], herbicida sistêmico pós-emergente e não-seletivo, é largamente usado na agricultura (DANIELE et al., 1997). Seus alvos incluem ervas de folhas largas anuais e perenes. Formulações comerciais do herbicida podem ser usadas nas entrelinhas de culturas de ameixa, cacau, café, citrus, maçã, nectarina, pêra, soja, uva, arroz, algodão, milho e em pastagens. Também pode ser empregado como dessecante em plantios diretos, como maturador de cana-deaçúcar e na eliminação de plantas aquáticas (AMARANTE JÚNIOR et al., 2002).

O glifosato é usado para alterar diferentes processos bioquímicos vitais em plantas, como a biossíntese de aminoácidos aromáticos, proteínas e ácidos nucléicos (GLASS, 1984). O herbicida é absorvido pelo tecido vivo e translocado, via floema, através da planta para as raízes e rizomas. Sua atuação nos vegetais inibe a ação da enzima específica enolpiruvil shikimato-3-fosfato sintase (EPSP), impedindo a síntese de aminoácidos aromáticos (DANIELE et al., 1997) que são precursores de outras substâncias como alcalóides, flavonóides e lignina (AMARANTE JÚNIOR et. al., 2002). As plantas tratadas com glifosato morrem lentamente, em poucos dias ou semanas, e devido ao seu transporte por todo o sistema nenhuma parte da planta sobrevive. A ausência dessa enzima no homem e nos animais torna o produto menos tóxico que os organofosforados.

A forma mais importante de degradação do glifosato ocorre pela ação de microrganismos. Existem duas vias principais de degradação microbiana desse herbicida. A primeira envolve a clivagem 
da ligação C-P da molécula pela ação da enzima C-P liase, produzida pela bactéria Agrobacterium radiobacter, que resulta em sarcosina. A segunda envolve a clivagem da molécula com produção de ácido aminometilfosfônico (AMPA) a partir da bactéria Flavobacterium sp (ARAÚJO, 2002). O tempo de meia-vida do glifosato no solo pode variar de dias até anos, dependendo do tipo de solo e dos microrganismos presentes.

Absorvido via oral ou dérmica, o herbicida é excretado principalmente pela urina. Irritante dérmico e ocular pode causar danos hepáticos e renais, quando ingerido em altas doses. Entre os efeitos agudos e crônicos em seres humanos encontram-se dermatite de contato e síndrome tóxica, após ingestão de altas doses epigastralgia (ulceração ou lesão de mucosa gástrica), hipertermia, anúria, oligúria, hipotensão, conjuntivite, edema orbital, choque cardiogênico, arritmias cardíacas, edema pulmonar não-cardiogênico, pneumonite, necrose tubular aguda, elevação de enzimas hepáticas, acidose metabólica e hipercalemia (AMARANTE JÚNIOR et al., 2002).

\section{BENZENAMINAS}

A substituição dos átomos de hidrogênio do anel benzênico por grupos funcionais amínicos origina as benzenomonaminas (fenilaminas), benzenodiaminas (fenilenodiaminas) e assim por diante, conforme a substituição ocorra por um, dois ou mais grupos amino (MIDIO e MARTINS, 1997). A introdução do radical nitro $\left(-\mathrm{NO}_{2}\right)$ nas posições 2 e 6 das benzenomonaminas origina as dinitrobenzenomonaminas, mais conhecidas por dinitroanilinas, das quais os derivados $\mathrm{N}, \mathrm{N}$-dialquil2,6-dinitroanilina apresentam maior importância comercial. Alguns derivados N-monoalquil-2,6dinitroanilina têm encontrado aplicação prática no controle de plantas daninhas, como a pendimetalina. Herbicida seletivo, pré e pós-emergente, a pendimetalina [N-1-(etil-propil)-2,6-dinitro-3,4-metil-toluidina] é utilizada no controle anual da maioria das gramíneas e de ervas daninhas de folhas largas em culturas de milho, batata, arroz, algodão, soja, tabaco, amendoim e girassol.

Pendimetalina apresenta afinidade por proteínas chamadas tubulinas. Essas proteínas mediante polimerização constituem os microtúbulos que fazem parte do citoesqueleto (responsável pelo formato tetraédrico característico das células vegetais). Também formam os fusos cromáticos responsáveis pela migração dos cromossomos da parte equatorial para os pólos das células durante a anáfase na mitose. Quando essas proteínas entram em contato com o produto, a formação dos microtúbulos é inibida. O resultado são células que não se dividem e passam a ser multinucleadas, como conseqüência ocorre a inibição do crescimento das plântulas e a morte (ANTHONY e HUSSEY, 1999).

Dinitroanilinas sofrem fotodecomposição, a qual ocorre predominantemente no estado de vapor. Assim, compostos mais voláteis são mais fotodegradáveis (ANTHONY e HUSSEY, 1999). Grande número de produtos é esperado da redução da pendimetalina. A redução do grupo nitro segue a progressão nitro $\rightarrow$ nitroso $\rightarrow$ hidroxilamina $\rightarrow$ amina (ARNOLD, 2004).

A degradação no solo pode ocorrer tanto em condições aeróbicas como anaeróbicas. Produtos da degradação desse herbicida, embora não identificados, mostraram-se mais polares que a própria pendimetalina. A biodegradação aeróbica ocorre pela desalquilação do grupo amino, seguido da redução do grupo nitrilo. Já sob condições anaeróbicas verifica-se a redução seqüencial dos grupos nitro (ARNOLD, 2004).

A intoxicação por pendimetalina ocorre pelo ar e pela ingestão de alimentos contaminados, ou simplesmente pelo contato direto com a pele. Levemente tóxico, a inalação de vapores ou de particulados desse pesticida pode ser moderadamente irritante para as mucosas da boca, do nariz, da garganta e dos pulmões (ETN, 2003). A molécula de pendimetalina, absorvida em pequenas quantidades pelo trato gastrointestinal, é eliminada sem modificações pelas fezes. Pequena quantidade absorvida é rapidamente metabolizada pelo fígado e pelos rins, sendo excretada pela urina na forma de metabólitos (ZULALIAN, 1990). O produto é tóxico para peixes e invertebrados aquáticos. Nos vegetais, a pendimetalina é absorvida pelas raízes das plantas e degradada por oxidação (WSSA, 1994). 


\section{TRIAZINAS}

Os herbicidas do grupo das triazinas compreendem cerca de $30 \%$ da produção mundial de pesticidas (CABRAL et al., 2003). As s-triazinas normalmente apresentam anel heterocíclico com seis membros, cujos átomos de $\mathrm{C}$ e $\mathrm{N}$ são simetricamente localizados (PACAKOVA, STULIK e JISKRA, 1996). Os nomes das s-triazinas e suas principais propriedades são primeiramente determinadas pelo substituinte na posição 2 no anel heterocíclico, sendo o -Cl o mais freqüente (nome comercial terminando em -azina), $-\mathrm{SCH}_{3}$ (-trina) e- $\mathrm{OCH}_{3}$ (-tona).

A atrazina (2-cloro-4-(etilamino)-6-(isopropilamino)-s-triazina), herbicida pré e pós-emergente, é importante representante do grupo das triazinas. Tem sido utilizada no controle anual de plantas daninhas em grande variedade de culturas, incluindo as de milho, cana-de-açúcar, sorgo e pinus. Devido ao uso intenso, baixa reatividade e solubilidade, é comumente detectado no monitoramento de solos e águas subterrâneas. Seus resíduos e metabólitos podem ser encontrados nesses locais após longo tempo de aplicação (MELI et al., 1992), pois seu tempo de vida médio varia de 20 até mais de 100 dias. Seus resíduos também são encontrados em frutas e vegetais (ATRAZINE..., 2004a).

A classificação dos mecanismos de ação de herbicidas depende do risco de desenvolvimento de resistência pelas espécies alvo. Os herbicidas do GRUPO C, inibidores do Fotossistema II, apresentam elevado número de biótipos resistentes. Considerando que os produtos são comercializados há mais de 40 anos, seu mecanismo de ação tornou-se menos suscetível ao desenvolvimento de resistência, sendo classificados como risco médio (CHRISTOFFOLET, OVEREJO e CARVALHO, 2004).

As triazinas pertencem ao grupo C1 (inibidores do Fotossistema II). Atuam na membrana do cloroplasto em que ocorre a fase luminosa da fotossíntese, mais especificamente no transporte de elétrons (CHRISTOFFOLET, OVEREJO e CARVALHO, 2004). As plantas que recebem aplicações desses herbicidas apresentam clorose foliar e tem o seu crescimento inibido.

A hidrólise química da atrazina, seguida de biodegradação, deve ser a rota mais importante de desaparecimento do composto em ambientes aquáticos (ETN, 2004). Alguns exemplos de microrganismos degradadores de triazinas são Pseudomonas sp, Rhodococcus spp., Ralstonia sp, Clavibactersp, Pseudomonas spp., Agrobacterium sp e Streptomyces sp (ATRAZINE..., 2004b).

O produto é levemente tóxico para humanos e outros animais. Pode ser absorvido oralmente, dermatologicamente e por inalação. Sintomas de envenenamento incluem dores abdominais, diarréia e vômitos, irritação nos olhos, irritação nas membranas das mucosas e erupções na pele. Praticamente atóxico para os pássaros e abelhas é levemente tóxico para os peixes e outros organismos aquáticos (ETN, 2004).

\section{ORGANOFOSFORADOS}

Os pesticidas organofosforados contêm, sem exceção, um átomo central de fósforo pentavalente ao qual está ligado um átomo de oxigênio ou enxofre mediante dupla ligação. Apresentam efeito tóxico mais agudo para os seres humanos e outros mamíferos do que os pesticidas organoclorados. Tal como os hidrocarbonetos clorados, os organofosforados concentram-se nos tecidos gordurosos.

Fenitrotion [O,O-dimetil-O-(3-metil-4-nitrofenil fosforotionato)], importante pesticida organofosforado, é empregado como inseticida e acaricida (THE PESTICIDE..., 2001). Tem sido utilizado em diversos tipos de plantações para combater pragas, nos domicílios contra moscas e mosquitos, além de empregado por órgãos de saúde pública no combate a vetores de doenças (por exemplo, controle do Aedes Aegypti, mosquito da dengue) (IPCS, 2001). Em plantações, é aplicado nas partes aéreas de culturas de alho, cebola, trigo, arroz, milho, frutos (exceto nozes), hortaliças, feijão, batata, algodão, amendoim, soja, cacau, café e centeio. O produto também serve para o tratamento de grãos armazenados e de farelo de trigo.

Os pesticidas organofosforados agem no sistema nervoso central do inseto, inibindo as enzimas 
colinesterases. Dentro dos neurônios, os sinais são transmitidos por impulsos elétricos mediante íons de sódio com carga positiva. Chegando aos nós sinápticos, os impulsos elétricos excitam as vesículas que repassam os sinais por mensageiros químicos para as células seguintes. As células nervosas usam diversos tipos de mensageiros químicos, sendo mais conhecidos o ácido gamaaminobutírico (GABA) que comunica as células nervosas com células musculares (CATÁLOGO..., 2004) e a acetilcolina, que transmite sinais entre células nervosas. Assim que o sinal químico é transmitido, a acetilcolina é removida da sinapse pela enzima colinesterase, deixando-a pronta para novo sinal. A seqüência desses eventos acontece em frações de segundo. A inibição da colinesterase ocorre principalmente por fosforilização da enzima, o que a deixa inativa. A inibição da atividade dessa enzima leva ao acúmulo de acetilcolina, provocando estimulação descontrolada do sistema nervoso e levando o inseto afetado à morte (CATÁLOGO..., 2004).

O Fenitrotion apresenta alta estabilidade sob condições ácidas e neutras em temperatura de $37^{\circ} \mathrm{C}$, porém é rapidamente hidrolisado em meio alcalino. Sua meia-vida é de três dias em condições fracamente alcalinas e menos de 24 horas em valores de $\mathrm{pH}$ acima de 11 (THE PESTICIDE..., 2001; IPCS, 2001).

Diferentes bactérias do solo e da água, incluindo Bacillus subtilis, Escherichia coli, E. freundii, Pseudomonas reptilovora e $P$. aeruginosa podem metabolizar ou inativar o fenitrotion. O produto da hidrólise desse pesticida pelo fungo Trichoderma viride (3-metil-4nitro-fenol) pode ser co-metabolizado por ele (ICPS, 2004).

O produto atua, principalmente, como inibidor da enzima acetilcolinesterase, provocando efeitos tóxicos acentuados no organismo humano e de animais. A rota de absorção de fenitrotion inclui o trato intestinal, contato com a pele e inalação. Após a ingestão, o agrotóxico apresenta rápida absorção pelo trato intestinal, sendo distribuído por várias partes do corpo. Foi observado que essa molécula é excretada pela urina (numa proporção de aproximadamente 90 a 95\%) e pelas fezes (de 5 a 10\%) (IPCS, 2001).

Os principais sintomas de intoxicação envolvem dores de cabeça, tremores, náuseas, câimbras abdominais, diarréia e suores. Os sintomas iniciais são seguidos por falta de clareza e escurecimento da visão, confusão, tensão no tórax e tosse, podendo também ocorrer edema pulmonar. Descontrole, falta de consciência e convulsões são indícios de envenenamento grave (THE PESTICIDE..., 2001). Alguns estudos mostraram que muitas perturbações ocasionadas por inseticidas organofosforados dependem do colesterol contido na membrana celular (alta taxa de colesterol impede a incorporação do inseticida) (KOBAYASHI, 1993).

\section{FENILPIRAZÓIS}

O inseticida fipronil (5-amino-1-[2,6-dicloro-4-(trifluormetil) fenil]-4-[(trifluormetil) sulfinil]-1H-pirazol3-carbonitrila) pertence a classe dos fenilpirazóis (TINGLE et al., 2004). É aplicado no solo em culturas de batata, cana-de-açúcar e milho, em folhas nas culturas de algodão, arroz, cana-de-açúcar, milho e soja, em sementes de arroz, cevada, soja e feijão e na água para irrigação de arroz. Também é utilizado como preservante de madeira, no controle de pulgas e carrapatos em animais e domesticamente contra baratas e formigas.

Extremamente ativo, o fipronil atua no sistema nervoso central do inseto inibindo o receptor do ácido gama aminibutírico (GABA). O sistema receptor-GABA, responsável pela inibição da atividade neural anormal, previne o estímulo excessivo dos nervos. Quando a função desse sistema regulador é bloqueada pelo fipronil ocorre hiperexcitação neural e conseqüentemente a morte do inseto (PAN, 2005).

O fipronil sofre degradação lenta em água e sedimentos em condições anaeróbias, com tempo de meia-vida variando entre 116 e 130 dias. É estável à hidrólise em pH moderadamente ácido a 
neutro. Em condições aeróbicas degrada-se lentamente mediante oxidação, redução e hidrólise (meio alcalino). Quando exposto a luz, o composto sofre fotodegradação e sua meia-vida é de 3,6 horas em água e 34 dias em solo argiloso. Produz diversos metabólitos (produtos da fotodegradação), dentre os quais o fipronil-dissulfinil que é extremamente estável e mais tóxico que o composto original (NPTN, 2005).

Altamente tóxico para peixes e invertebrados aquáticos, o fipronil é moderadamente tóxico para pequenos mamíferos quando ingerido. Apresenta tendência para se ligar aos sedimentos e baixa solubilidade em água que podem reduzir sua toxicidade. É atóxico para minhocas, microrganismos do solo e plantas aquáticas (NPIC, 2004). Em relação à saúde humana existem poucos dados, contudo células humanas foram usadas em alguns estudos de carcinogenicidade nos quais nenhum efeito adverso foi detectado (PAN, 2005).

O fipronil é absorvido pelo trato gastrointestinal e rapidamente metabolizado. A concentração máxima do fipronil no sangue ocorre de 4 a 6 horas após sua ingestão e começa a declinar lentamente (processo de eliminação lento). A excreção do fipronil e de seus metabólitos ocorre principalmente pelas fezes e em menor quantidade pela urina (FIPRONIL..., 2005).

\title{
7 CONCLUSÃO
}

No Brasil são utilizados vários pesticidas, além dos citados nesta revisão. Tratando-se de país extremamente agrícola torna-se importante estudar os mecanismos de ação e as transformações que esses pesticidas sofrem no ambiente, mas principalmente sua toxidez para o homem.

Os mecanismos de ação dos pesticidas abordados incluem a inibição de enzimas especifícas como a enolpiruvil shikimato-3-fosfato sintase (glifosato) e a colinesterase (fenitrotion), de proteínas como as tubulinas (pendimetalina), de receptores do sistema nervoso como o ácido gama aminibutírico (fipronil) e da inibição da fotossíntese (atrazina).

Em relação à degradação, a rota mais importante para o desaparecimento dos herbicidas glifosato e atrazina e do inseticida fenitrotion é a biodegradação. Fipronil, moderadamente persistente no ambiente, é degradado pela luz (fotodegradação). Para a pendimetalina, tanto os microrganismos quanto a luz são responsáveis pelo desaparecimento desse composto.

A toxidez dos pesticidas varia de acordo com o grupo químico em que se enquadram, sendo o efeito tóxico mais agudo para os seres humanos e outros mamíferos apresentado pelo fenitrotion (organofosforado).

\begin{abstract}
PESTICIDES: ACTION MECHANISM, DEGRADATION AND TOXICITY

This paper supplies a compact revision of some pesticides of wide use in Brazil in soy, corn and sugar cane cultures. The action mechanism, the degradation and the toxicity of the herbicides glyphosate, pendimethalin, atrazine, fenitrothion and fipronil were approached. It was verified that the action mechanism of these pesticides occur through the inhibition of specific enzymes as enolpyruvyl shikimate-3-phosphate synthase (glyphosate) and cholinesterase (fenitrothion), of proteins as the tubulines (pendimethalin), of nervous system receptor as GABA (fipronil) and photosynthesis inhibition (atrazine). In relation to the degradation, glyphosate, atrazine and fenitrothion present the biodegradation as more important route for the disappearance of these substances. Fipronil is shown moderately persistent in the environmental, being the light the responsible for its degradation (photodegradation). For the pendimethalim as much the microorganisms as the light are responsible for the disappearance of this compound. The toxicity of these pesticides varies in agreement with the chemical group which they are classified, being more acute toxic effect for the human and mammals presented by fenitrothion (organophosphate).
\end{abstract}

KEY-WORDS: PESTICIDES - ACTION MECHANISM; DEGRADATION; PESTICIDES - TOXICITY. 


\section{REFERÊNCIAS}

1 JONATAN, T. Introduction of environmental studies. $3^{\text {rd }}$ ed. New York: Saunders College, 1989. $304 \mathrm{p}$.

2 SILVA, S. C. Brasil é o quarto maior consumidor de agrotóxicos. O Estado de São Paulo, 18.jul.1999, p. A16, Geral Ambiente.

3 ROMAN, E. S. Mecanismos de ação de herbicidas. Disponível em: http://www.cnpt.embrapa.br/ f_danin. Acesso: 10 de mar. 2004.

4 DANIELE, P. G.; STEFANO, C.; PRENESTI, E.; SAMMARTANO, S. Copper(II) complexes of N(phosphonomethyl)glycine in aqueous solution: a thermodynamic and spectrophotometric study. Talanta, v. 45, n. 2, p. 425-431, 1997.

5 AMARANTE JÚNIOR, O. P.; SANTOS, T. C. R.; BRITO, N. M.; RIBEIRO, M. L. Glifosato: propriedades, toxicidade, usos e legislação Quím. Nova, v. 25, n.4, p.589-593, 2002.

6 GLASS, R. L. Metal-complex formation by gliphosate. J. Agric. Food Chem., v.32, n.6, p. 1249$1253,1984$.

7 ARAÚJO, A. S. F. Biodegradação, extração e análise de glifosato em dois tipos de solos. Piracicaba, 2002. 83 p. Dissertação (Mestrado em Agronomia), Escola Superior de Agricultura "Luiz de Queiroz", Universidade de São Paulo.

8 MIDIO, A. F.; MARTINS, D. I. Herbicidas em alimentos. São Paulo: Livraria Varela, 1997.

9 ANTHONY R. G.; HUSSEY P. J. Dinitroaniline herbicide resistance and the microtubule cytoskeleton. Trends in Plant Science, v. 4, n.3, p. 112-116, 1999.

10 ARNOLD, W. A. Investigation of the abiotic reduction of the herbicides trifluralin and pendimethalin. Disponível em: http://water.usgs.gov/wrri/00grants/MNabiotic.pdf. Acesso: 15 Ago. 2004.

11 ETN. Extension Toxicology Network. Pesticide Information Profiles. Disponível em: http:// extoxnet.orst.edu/pips/pendimet.htm. Acesso: 05 Mar. 2003.

12 ZULALIAN, J. Study of the absorption, excretion, metabolism, and residues in tissues in rats treated with carbon-14-labeled pendimethalin, prowl herbicide J. Agric. Food Chem., v.38, n.8, p. 17431754, 1990.

13 WSSA. Weed Science Society of America. Herbicide Handbook. $7^{\text {th }}$ ed. Champaign, 1994. p. 10-59.

14 CABRAL, M. F.; SOUZA, D.; ALVES, C. R.; MACHADO, S. A. S. Estudo do comportamento eletroquímico do herbicida ametrina utilizando a técnica de voltametria de onda quadrada. Eclética Química, v.28, n.2, p.41-47, 2003.

15 PACAKOVA, V.; STULIK, K.; JISKRA, J. High-performance separations in the determination of triazine herbicides and their residues. J. Chromatogr. A. v 754, n. 1-2, p. 17-31, 1996.

16 MELI, G.; BAGNATI, R.; FANELLI, R.; BENFENATTI, E.; AIROLDI, L. Metabolic profile of atrazine and Nnitrosoatrazine in rat urine. Bull. Environ. Contam. Toxicol., v.48, n.5, p. 701-708, 1992.

17 ATRAZINE in Vermont: carcinogen \& endocrine disruptor. Disponível em: http://www.sover.net/ dogstar/atrazin2.html. Acesso: 20 Jan. 2004a.

18 CHRISTOFFOLET, P. J.; OVEREJO, R. F. L.; CARVALHO, J. C. Aspectos de resistência de plantas daninhas a herbicidas. 2. ed., Campinas: Associação Brasileira de Ação à Resistência de Plantas aos Herbicidas, 2004.

19 ETN. Extension Toxicology Network. Pesticide Information Profiles: atrazine. Disponível em: http:// extoxnet.orst.edu/pips/atrazine.htm. Acesso: 20 Ago. 2004.

20 ATRAZINE Pathway Map. Disponível em: http://umbbd.ahc.umn.edu/atr/atr_map.html. Acesso: 21 Ago. 2004b. 
21 THE PESTICIDE Management Education Program at Cornell University. Fenitrothion. Disponível em: http://pmep.cce.cornell.edu/profiles/insect-mite/fenitrothion-methylpara/fenitrothion/insect-proffenitrothion.html. Acesso: 02 Set. 2001.

22 IPCS. International Programme on Chemical Safety. Fenitrothion. Disponível: http://www.inchem.org/ documents/pds/pds/pest30_e.htm. Acesso em 02 Set. 2001.

23 CATÁLOGO de produtos fitossanitários: organofosforados. Disponível em: http://www.basf.com.br/ cat_eletronico/herb_modo_dinitro.htm. Acesso: 15 Ago. 2004.

24 IPCS. International Programme on Chemical Safety. Environmental Heath Criteria 133: fenitrothion. Disponível em: http://www.inchem.org/documents/ehc/ehc/ehc133.htm. Acesso: 10 Ago. 2004.

25 KOBAYASHI, K.; WANG, Y.; KIMURA, S.; ROMPAS, R.M.; IMADA, N.; OSHIMA, Y. Mechanism of the reduction of fenitrothion toxicity in kuruma prawn by piperonyl butoxide. Nippon Suisan Gakkaishi, v.59, n. 9, p. 1581-1585,1993.

26 TINGLE, C. C. D.; ROTHE, J.A.; DEWHURST, C.F.; LAUER, S.; KING, W.J. Health and environmental effects of fipronil. Disponível em: http://www.pan-uk.org/briefing/fipronil.pdf. Acesso: 12 Ago. 2004.

27 PAN. Pesticide Action Network UK Journal. Fipronil. Disponível em: http://www.pan-uk.org/pestnews/ actives/fipronil.htm. Acesso: 29 Nov. 2005.

28 NPTN. National Pesticide Telecommunications Network. Fipronil. Disponível em: http://npic.orst.edu/ factsheets/fipronil.pdf. Acesso: 29 Nov. 2005.

29 NPIC. National Pesticide Information Center. Fipronil. Disponível em: http://www.ace.orst.edu/info/ nptn. Acesso: 12 Ago. 2004.

30 FIPRONIL Toxicity. Development of a Cross-linked copepod life-cycle and molecular-genetic assay for examining exposure and effects of coastal use insecticides. Disponível em: http:// www.biol.sc.edu/ coull_lab/staton/ab17.html. Acesso: 29 Sep. 2005.

\section{AGRADECIMENTOS}

Os autores agradecem à FAPESP, CAPES e CNPq pelas bolsas e apoio financeiro. 